\title{
ANATOMY OF RECURRENT LARYNGEAL NERVE IN THYROIDECTOMY
}

\author{
Ramraj $R^{1}$, Vishnu $M L^{2}$
}

${ }^{1}$ Senior Consultant Surgeon, Department of General Surgery, SUT Hospital, Pattom, Thiruvananthapuram. 2 Assistant in the Department, Department of General Surgery, SUT Hospital, Pattom, Thiruvananthapuram.

\begin{abstract}
BACKGROUND

Thyroid surgeries have been through tremendous evolution to make it a safe procedure. Thyroid surgery can today be performed with practically no added mortality other than the risk of general anaesthesia. A likely voice problem is a fearful dream from patient's point of view. In order to overcome this problem and to achieve enviable results, the surgeon should have in-depth knowledge of the anatomy of the neck especially of the laryngeal nerves, the pathophysiology of thyroid disorders, be versed in the pre and postoperative care of the patient and finally use an unhurried careful, meticulous operative technique adhering to the principles of capsular dissection.
\end{abstract}

\section{MATERIALS AND METHODS}

The objective of the study is to delineate the various patterns of anatomy of recurrent laryngeal nerve as visualised during thyroidectomy and to assess the incidence of injury to the nerve with total visualisation of the nerve in its entire course in different thyroid disorders. This descriptive study was conducted on 213 patients in the Department of General Surgery.

\section{RESULTS}

Among 213 patients who underwent thyroidectomy, 35.71\% (135) RLN found as a single trunk, 43.65\% (165) RLN branching into two, 20.64\% (78) RLN branching into more than two. Relation of RLN to ITA, $21.16 \%, 73.54 \%$ and $5.3 \%$ for anterior to main stem, posterior to main stem and between the branches respectively. Relation of RLN to TOG towards right and left were $73.58 \%, 21.76 \%$, $4.66 \%$ and $81.08 \%, 15.68 \%, 3.24 \%$ in regard to RLN exactly in TOG lateral to TOG and anteromedial to TOG respectively. 1 (2.816 $\%$ ) had injury to RLN; $23.02 \%, 15.08 \%$ and $61.90 \%$ were the percentages of mode of entry into larynx through Berry's ligament, posteromedial to Berry's ligament and lateral to Berry's ligament respectively.

\section{CONCLUSION}

Recurrent laryngeal nerve injury represents the main damage of the thyroid surgery. The only option to safeguard the nerve is to identity the nerve than to avoid it. The best pattern to identify the nerve is to use Inferior thyroid artery as the anatomical landmark. Identification of the nerve has to be in its entirety. Most common site of recurrent laryngeal nerve injury is at its entry into larynx close to the Berry's ligament. Bilateral symmetry of the nerve is an evident fact.

\section{KEYWORDS}

Recurrent Laryngeal Nerve Anatomy, Ligament of Berry, Tracheo-Oesophageal Groove.

HOW TO CITE THIS ARTICLE: Ramraj R, Vishnu ML. Anatomy of recurrent laryngeal nerve in thyroidectomy. J. Evolution Med. Dent. Sci. 2017;6(95):7009-7014, DOI: 10.14260/jemds/2017/1521

\section{BACKGROUND}

The extirpation of the thyroid gland typifies, perhaps better than any operation, the supreme triumph of the surgeon's art. A feat which today can be accomplished by any competent operator without danger of mishap and which was conceived more than one thousand years ago. There are operations today perhaps more delicate and more difficult. But is there any operative problem propounded so long ago and attacked by so many, which has yielded results as bountiful and so adequate?

\section{Dr. William S. Halsted $1920^{1}$}

In the 97 years since these words were written, the ever so many improvements have made thyroidectomy ${ }^{2,3}$ safer and

'Financial or Other Competing Interest': None.

Submission 14-11-2017, Peer Review 08-12-2017,

Acceptance 14-12-2017, Published 23-12-2017.

Corresponding Author:

Dr. Ramraj R,

Senior Consultant Surgeon

Department of General Surgery,

SUT Hospital, Pattom, Thiruvananthapuram.

E-mail: ramrajr69@gmail.com

DOI: $10.14260 /$ jemds/2017/1521

\section{(c) (i) $(2)$}

easier. In fact, in the best of hands, thyroid surgery can today be performed with practically no added mortality other than the risk of general anaesthesia. A likely voice problem is a fearful dream from patient's point of view. In order to overcome this problem and to achieve enviable results, the surgeon should have in-depth knowledge of the anatomy of the neck especially of the laryngeal nerves, the pathophysiology 4,5 of thyroid disorders, be versed in the pre and postoperative care of the patient and finally use an unhurried careful, meticulous operative technique adhering to the principles of capsular dissection. ${ }^{6}$

An attempt for a thorough evaluation of the finer anatomy of recurrent laryngeal nerve is made in this study.

\section{Finer Anatomy of Recurrent Laryngeal Nerve}

Galeno of Pergamo ${ }^{6}$ was the first anatomist to describe the recurrent laryngeal nerve as a branch of a cranial nerve. Vesalio $^{6}$ and Willis described the anatomy of larynx and recurrent laryngeal nerve as they are found in standard text books today. Lahey ${ }^{6}$ emphasised the importance of developing a standard technique of identification and preservation of recurrent laryngeal nerve in thyroidectomies. 
The RLN carries motor, sensory and parasympathetic fibres. The internal branch of the nerve supplies sensation to the vocal folds and subglottic region; the external branch provides motor function to the intrinsic muscles of larynx (thyroarytenoid, lateral and posterior cricoarytenoids,) and the transverse is supplied by the external branch of the superior laryngeal nerve. During the ascent of the nerve from the thorax to the neck and its entry into larynx various anatomical variations are encountered. These have been addressed under the following headings.

\section{a) Presence or absence of branches}

Many studies report that the nerve usually divides into two or more branches; when approaching the inferior constrictor muscle before entering the larynx.

Rustard 6 in his autopsy studies on hundred cadavers noted that $43 \%$ of RLN divided into two or more branches on both sides and the anterior division may pass either anteriorly or posteriorly to the cricothyroid articulation and then coursing along the cricoarytenoid muscle innervates all the intrinsic muscles of larynx except cricothyroid. The posterior branch usually innervates the posterior cricoarytenoids and the arytenoids muscles.

\section{b) Relation of the RLN to the main stem of inferior thyroid artery}

When approaching the inferior pole of the gland the RLN may pass posterior to the inferior thyroid artery, anterior to it or may pass between the arterial ramifications or rarely may pass through ${ }^{7}$ the gland.

Steinberg JL reported in 1986 that the RLN passed posterior to ITA in $61.5 \%$; anterior to ITA in $32.5 \%$ and between the branches of ITA in $6.5 \%$.

Marginal differences ${ }^{8}$ are there in various contemporary studies but all authors agree that the RLN most commonly lies deep to the artery in its course of ascent to the larynx.

\section{c) Position in relation to tracheo-oesophageal groove} Significant variations were demonstrable in the relationship between the RLN and trachea-oesophageal groove on either side.

Hunt $^{9}$ et al reported in 1968 that on the right side the RLN ascending in the neck was located in tracheo-oesophageal groove in $65 \%$ and on the left side the anatomy was maintained in $77 \%$. In $33 \%$ of cases, the nerve was located lateral to the trachea or the side (RT); whereas the left side the nerve was lateral to the trachea in $22 \%$ of cases. Very rarely the nerve was found ascending anterolateral to trachea (in less than $1 \%$ of cases), making the nerve vulnerable to surgical injury.

\section{d) Relationship between the recurrent laryngeal nerve and the ligament of Berry}

The nerve at its entry into larynx close to ligament of Berry is vulnerable for injury during thyroidectomy; either due to fraction of ligation of branches of inferior thyroid artery flush with ligament of Berry.

Berlin D in 1935 in his study published in Surgery, Gynaecology-Obstetrics showed that $30 \%$ of nerves (RLN) passed through the ligament of Berry.
The observation in majority was the RLN either passed up to $3 \mathrm{~mm}$ from ligament of Berry or came closer to it.
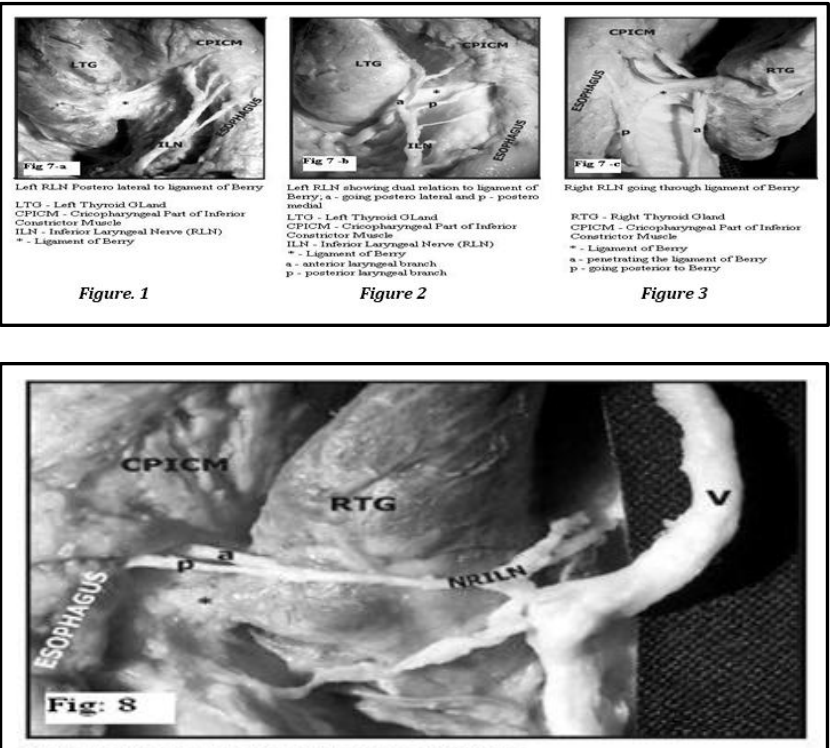

Non Recurrent Recurrent Laryngeal Nexve

RTG - Right Thyroid Gland

CPICM - CricoPharyngeal Part of Inferior Constrictor Muscle NRILN - Non Recurrent Inferior Laryngeal Nerve

a-anterior branch

p- posterior branch

v - intemal jugular vein

Figure 4

The Mechanisms of RLN Damage ${ }^{10}$ in most Cases have been found in the Two Ways

1. During glandular traction, the nerve is vulnerable to injury especially when it is embedded in the gland.

2. Haemostatic sutures used for suturing the remnant gland especially after subtotal thyroidectomy can enclose the nerve and cause significant damage.

All the studies agree that the most common site of nerve injury (RLN) during thyroidectomy is at the area of ligament of Berry when the nerve enters the larynx and its knowledge is absolutely mandatory to avoid injury to the nerve.

\section{Study Design and Methods}

This descriptive study was conducted on patients admitted in the Department of Surgery. 213 patients were included in this study from January 2015 to December 2016. A uniform pattern of thyroidectomy was performed.

In all patients admitted for thyroidectomy a thorough physical examination was made and salient points in history were recorded. All patients underwent routine blood examination consisting of haemoglobin estimation, total count, differential leucocyte count, ESR, blood sugar, blood urea, serum creatinine, serum sodium, serum potassium. X-ray chest and ECG (all leads) were included in the list of investigations. Thyroid functional status was assessed by estimation of T3, T4, TSH in all cases and fT3 and fT4 in indicated cases. Preoperative cytopathological diagnosis was obtained by fine needle aspiration cytology. Serum calcium was also estimated in indicated cases. Thyroid antibodies, USG of thyroid and CT scan of neck were also performed when needed. 


\section{Operative Technique}

Apart from the conventional technique mentioned in books, surgeons adopt certain modifications. After division and ligation of the middle thyroid veins; medial rotation of the thyroid gland is done. Inferior thyroid artery is identified as it emerges behind the common carotid artery; and it is dissected out in an atraumatic fashion and looped with 2.0 Vicryl.

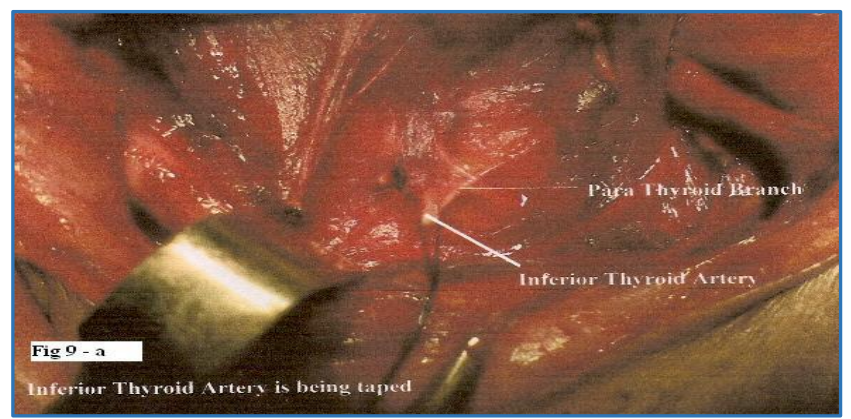

Figure 5. Inferior Thyroid Artery being Taped

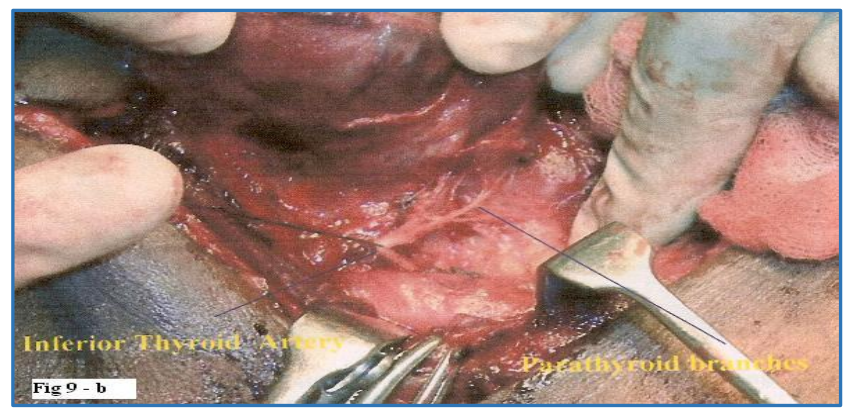

Figure 6

Using this loop as a gentle retractor the artery is dissected forwards. The parathyroid artery emerging from the posteroinferior aspect of the main stem of inferior thyroid artery is identified and preserved.

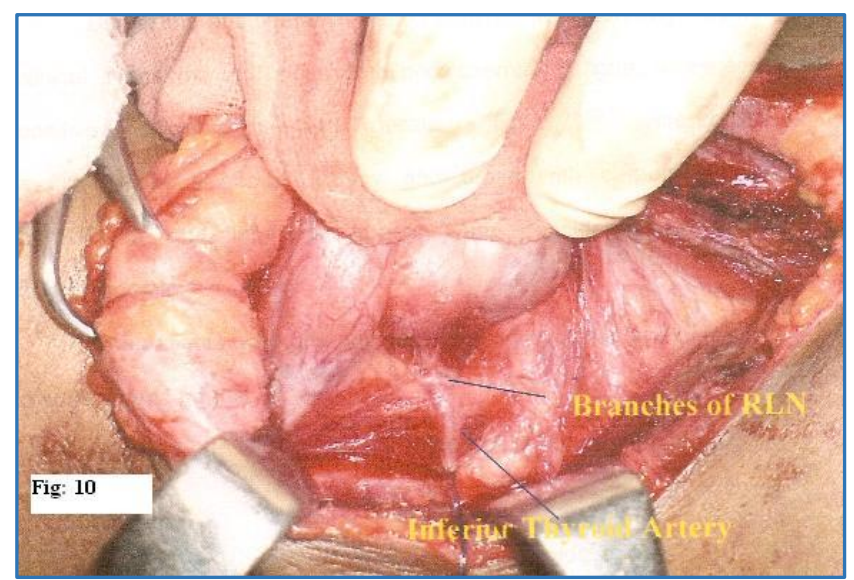

Figure 7

As the dissection proceeds the recurrent laryngeal nerve is encountered, it is safeguarded and dissected out in its full course from the root of neck till its entry into larynx. The branches of inferior thyroid artery distal to the parathyroid supply is controlled with bipolar cautery at the most distal point.

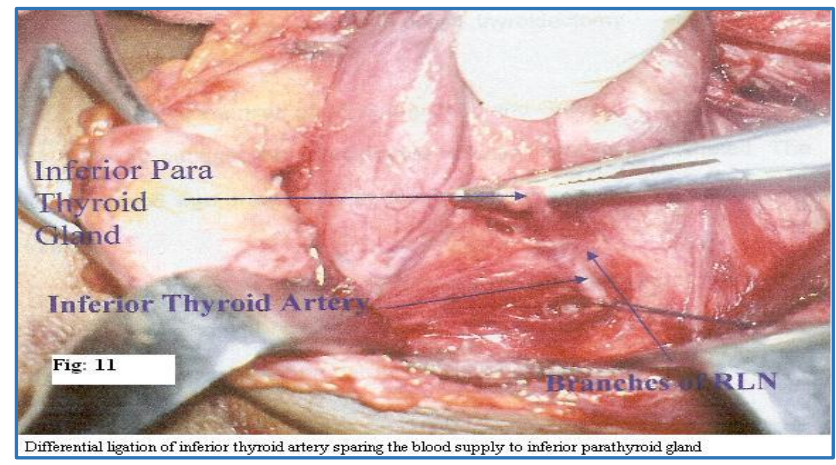

Figure 8. Differential Ligation of Inferior Thyroid Artery Sparing the Blood Supply to Inferior Parathyroid Gland

The finer aspects of anatomy of the recurrent laryngeal nerve namely presence or absence of branches, relation of the nerve to the main stem of inferior thyroid artery; position in relation to the tracheo-oesophageal groove, mode of entry into the larynx with reference to the ligament of Berry and chances of bilateral symmetry were observed. The data were collected using the standard proforma and they were analysed to arrive at the observations.

\section{Ethics}

All the procedures followed in the study were in accordance with the ethical standards. Consent from ethical committee was sought to carry out the study.

\section{RESULTS}

The patients in this study were grouped into three categories according to the type of surgery done on them.

\begin{tabular}{|c|c|c|}
\hline Group I & Total thyroidectomy & 165 \\
\hline Group III & Hemithyroidectomy & 48 \\
\hline \multicolumn{2}{|c|}{ Total Population } & $\mathbf{2 1 3}$ \\
\hline
\end{tabular}

*Patient profile is given in Table I

The Observation in this Study were-

Incidence of Recurrent Laryngeal Nerve Injury was $\mathbf{2 . 8 1 6 \%}$

1 out of 213 patients had injury to RLN

This patient had injury to the terminal branches of RLN just before its entry into larynx; close to the Berry's ligament when the ligament was ligated. The injury was confirmed on the table, no attempt of primary repair was done as it was very fine branch of the RLN. There was minimal voice change, but improved slowly.

\section{External Laryngeal Nerve (ELN)}

The external laryngeal nerve could be identified only in 156 out of 213 cases, i.e. $73.2 \%$.

\section{Anatomy of RLN}

Of the 378 nerves dissected on either side from 213 cases; 193 nerves were on the right side and 185 nerves were on left side. 1 non-recurrent recurrent laryngeal nerve was found in this study. 
The different findings with regard to the Finer Anatomy of RLN were-

\section{- Branching}

- No branches: (RLN found as a single trunk) observed in $35.71 \%$ ( 135 out of 378 nerves) i.e. 72 on the right and 63 on the left side.

- RLN branching into two: Observed in $43.65 \%$ (165 out of 378 nerves); 86 on the right side and 79 on the left side.

- $\quad$ RLN Branching into more than Two: Observed in $20.64 \%$ (78 out of 378 nerves); 35 on the right side and 43 on the left side.

- Relation of RLN to Inf. Thyroid Artery (ITA)

- RLN anterior to the main stem of ITA: Seen in $21.16 \%$ ( 80 out of 378 nerves); 38 on the right side and 42 on left side.

- RLN posterior to the main stem of ITA: Seen in $73.54 \%$ ( 278 out of 378 nerves); 148 on the right side and 130 on left side.

- RLN between branches of ITA: Seen in 5.29\% (20 out of 378 cases); 11 on the right side and 9 on the left side.

- Position of RLN in Relation to Tracheo-oesophageal Groove (TOG)

- $\quad$ RLN falling exactly in TOG: 73.57\% (142 nerves) on the right side and $81.08 \%$ (150 nerves) on the left side

- RLN falling lateral to TOG: seen in $21.76 \%$ (42 cases) on the right side and $15.67 \%$ (29 cases) on the left side.

- RLN was anteromedial to the TOG in 4.67\% (9 cases) on the right side and $3.25 \%$ ( 6 cases) on the left side.

- Mode of Entry of RLN into Larynx

- Through Berry's Ligament: In 23\% cases the RLN went through Berry's ligament (87 out of 378 nerves); 52 on the right side and 35 on left side.

- Posteromedial to Berry's ligament: $15.07 \%$ (57 out of 378 nerves); 34 on right side and 23 on left side.

- Posterolateral to Berry's ligament: In $61.9 \%$ (234 out of 378 nerves); 107 on the right side and 127 on the left side.

- Bilateral Symmetry

Bilateral symmetry was observed in 14.03\%; in 24 patients out of 171 patients in whom dissection was possible on both sides in the same patient.

\begin{tabular}{|c|c|c|}
\hline Groups & Surgery & Number of Patients \\
\hline I & Total Thyroidectomy & 165 \\
\hline II & Hemithyroidectomy & 48 \\
\hline \multicolumn{2}{|c|}{ Total } & 213 \\
\hline \multicolumn{2}{|c|}{ Table 1. Patient Profile } \\
\hline
\end{tabular}

\begin{tabular}{|c|c|c|}
\hline Author & Journal & Types \\
\hline \multirow{3}{*}{ Cornea } & $\begin{array}{c}\text { American Journal of Surgery, } \\
1992\end{array}$ & I $-60 \%$ \\
\cline { 2 - 3 } & & II a - 6\% \\
\cline { 2 - 3 } & & II b - 14\% \\
\hline Freidman & Head and Neck surgery 2002 & I - 60\% \\
\hline
\end{tabular}

\begin{tabular}{|c|c|c|}
\hline & & II - 18\% \\
\hline \multirow{2}{*}{ Furlan J. C } & $\begin{array}{c}\text { Archives of Head and Neck } \\
\text { Surgery 2003 }\end{array}$ & I - 42\% \\
\cline { 2 - 3 } & \multicolumn{2}{|c|}{ II - 20\% } \\
\hline \multicolumn{2}{|c|}{ Table 2. External Laryngeal Nerve types } \\
\hline
\end{tabular}

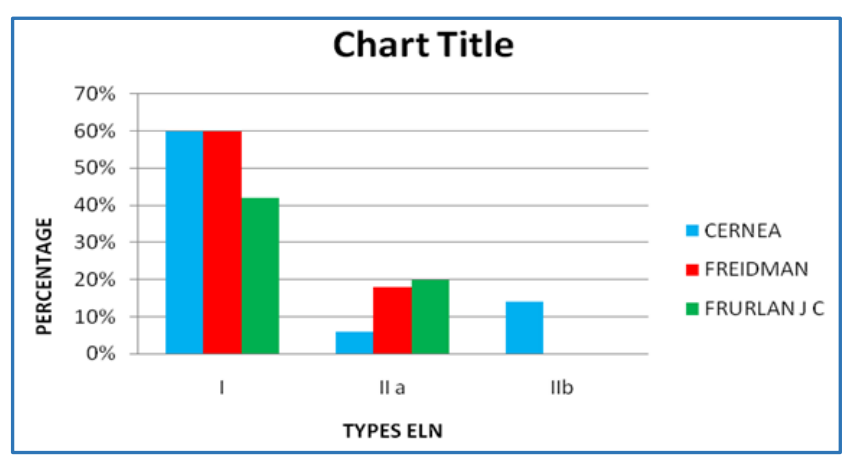

Figure 9. Types of ELN

\begin{tabular}{|c|c|c|c|}
\hline Side & $\begin{array}{c}\text { No. } \\
\text { branching }\end{array}$ & $\begin{array}{c}\text { Branching into } \\
\text { Two }\end{array}$ & $\begin{array}{c}\text { More than Two } \\
\text { Branches }\end{array}$ \\
\hline Right & 72 & 86 & 35 \\
\hline Left & 63 & 79 & 43 \\
\hline Percentage & $35.71 \%$ & $43.65 \%$ & $20.64 \%$ \\
\hline \multicolumn{3}{|c|}{ Table 3. Branching Pattern of RLN } \\
\hline
\end{tabular}

\begin{tabular}{|c|c|c|c|}
\hline Side & $\begin{array}{c}\text { Anterior to } \\
\text { Main Stem of } \\
\text { ITA }\end{array}$ & $\begin{array}{c}\text { Posterior to } \\
\text { Main Stem of } \\
\text { ITA }\end{array}$ & $\begin{array}{c}\text { Between the } \\
\text { Branches of } \\
\text { ITA }\end{array}$ \\
\hline Right & 38 & 148 & 11 \\
\hline Left & 42 & 130 & 9 \\
\hline Percentage & $21.16 \%$ & $73.54 \%$ & $5.3 \%$ \\
\hline
\end{tabular}

Table 4. Relation of RLN to Inferior Thyroid Artery (ITA)

\begin{tabular}{|c|c|c|c|c|}
\hline & \multicolumn{2}{|c|}{ Right } & \multicolumn{2}{c|}{ Left } \\
\hline & No. & \% & No. & \% \\
\hline RLN exactly in TOG & 142 & $73.58 \%$ & 150 & $81.08 \%$ \\
\hline RLN lateral to TOG & 42 & $21.76 \%$ & 29 & $15.68 \%$ \\
\hline $\begin{array}{c}\text { RLN anteromedial to } \\
\text { TOG }\end{array}$ & 9 & $4.66 \%$ & 6 & $3.24 \%$ \\
\hline
\end{tabular}

Table 5. Relation of RLN to Tracheo-oesophageal Groove (TOG)

\begin{tabular}{|c|c|c|c|}
\hline Side & $\begin{array}{c}\text { Through } \\
\text { Berry's } \\
\text { ligament }\end{array}$ & $\begin{array}{c}\text { Posteromedial } \\
\text { to Berry's } \\
\text { ligament }\end{array}$ & $\begin{array}{c}\text { Lateral to } \\
\text { Berry's } \\
\text { ligament }\end{array}$ \\
\hline Right & 52 & 34 & 107 \\
\hline Left & 35 & 23 & 127 \\
\hline Percentage & $23.02 \%$ & $15.08 \%$ & $61.90 \%$ \\
\hline \multicolumn{4}{|c|}{ Table 6. Mode of Entry into Larynx } \\
\hline
\end{tabular}

\begin{tabular}{|c|c|c|}
\hline $\begin{array}{c}\text { Total Cases } \\
\text { Studied }\end{array}$ & $\begin{array}{c}\text { Cases of RLN Dissection } \\
\text { done on Both Sides }\end{array}$ & $\begin{array}{c}\text { Bilateral } \\
\text { Symmetry }\end{array}$ \\
\hline 213 & 171 & 24 \\
\hline \multicolumn{3}{|c|}{ Table 7. Bilateral Symmetry } \\
\hline
\end{tabular}

\begin{tabular}{|c|c|c|c|c|}
\hline $\begin{array}{c}\text { Sl. } \\
\text { No. }\end{array}$ & Author & $\begin{array}{c}\text { Journal \& } \\
\text { Year }\end{array}$ & $\begin{array}{c}\text { With } \\
\text { identification } \\
\text { of RLN }\end{array}$ & $\begin{array}{c}\text { Without } \\
\text { identification } \\
\text { of RLN }\end{array}$ \\
\hline 1 & $\begin{array}{c}\text { Havid } \\
\text { Gaard }\end{array}$ & $\begin{array}{c}\text { Laryngoscope, } \\
1984\end{array}$ & $0.3-2 \%$ & $3-9.4 \%$ \\
\hline 2 & Wagner & B.J.S, 1988 & $3.8 \%$ & $9 \%$ \\
\hline 3 & Jatsko & Surgery, 1996 & $1.2 \%$ & $7.2 \%$ \\
\hline \multicolumn{4}{|c|}{ Table 8. Incidence of RLN Injury in Different Studies } \\
\hline
\end{tabular}




\section{DISCUSSION}

From the very words of Dr. William S Halsted in 1920, it is certain that there is no other surgical procedure done till date about which such an extent of discussion and dispute have taken place. All these have come into being just because of one single reason - the complex anatomy of the recurrent laryngeal nerve and the parathyroids. The injury to the external laryngeal nerve or recurrent laryngeal nerve does cause significant problem in the patient. The incidence of RLN injury is a correct tool in assessing the quality of the surgical technique performed.

The incidence of RLN injury does vary significantly with and without identification and dissection of the nerve in its full course during thyroidectomy. This is evident from the various publications as given in Table 8.

There is a remarkable difference in the incidence of RLN injury with total visualisation of the RLN. The incidence of RLN injury in this study was $2.816 \%$ with total visualisation of the nerve in its entire course. The external laryngeal nerve could be identified in $73.2 \%$ of cases.

As found in the autopsy studies of Rustard and the work of Nemiroff, the RLN did show branching. Dominant pattern in this study was that the nerve branched into two in $43.65 \%$. Weeks in his experience published in 1970 said 48\% of RLN showed branches. The finding in this study was comparable with the previous publications.

In the relationship between RLN and inferior thyroid artery the predominant pattern observed was that majority of RLN passed posterior to the main stem of inferior thyroid artery. This finding is comparable with the results of Steinberg J.L and Hollished. In the study of Hunt et al published in 1968 the majority of RLN fell in TOG (65\% on the right side and $77 \%$ on the left side). In this study, $70 \%$ to $80 \%$ of the nerves fell in the TOG itself. The RLN falling anteromedial to TOG was found in 9 cases on the right side. The RLNs which were injured in total thyroidectomy for papillary carcinoma in this study fell into this group.

In the evaluation of mode of entry of the nerve into larynx, the relationship with Berry's ligament was elucidated. Nearly $70 \%$ of the nerves passed posterolateral to the ligament of Berry. This finding was comparable with the latest publication in Journal of American College of Surgeons and contrary to the findings of Berlin and Lore J M. Berlin and Lore J M in their studies had majority of the nerves going through the ligament of Berry ranging from $30 \%$ to $44 \%$. In this study, only $23 \%$ of the nerves went through the ligament of Berry.

\section{Bilateral Symmetry}

In this study, dissection of recurrent laryngeal nerves on both sides in the same patient for assessment of bilateral symmetry was possible in 171 patients. In 24 such cases (14.03\%), bilateral symmetry could be demonstrated. There is no previous study available to make a comparison in reference to bilateral symmetry. Though theoretically bilateral symmetry is not a common entity, this study demonstrated a rather high occurrence of bilateral symmetry.

The observations in this study have been found to be comparable with most of the previous studies. Similar studies published are given below.

\section{CONCLUSION}

- Recurrent Laryngeal Nerve injury represents the main damage of thyroid surgery.

Vocal cord paralysis as a result of injury of main stem of RLN is rarer compared to a change in quality of voice as a result of injury to the branches of RLN.

- The only option to safeguard the Recurrent Laryngeal Nerve against damage is to identify the nerve than to avoid the nerve.

Avoiding the nerve puts the nerve at risk of damage during dissection due to the high incidence of anatomical variations.

- The best pattern for identifying the nerve is to find the Inferior Thyroid Artery as an anatomical marker. Though inferior thyroid artery has been mentioned as an important landmark in thyroidectomy, its befitting application in identification of the recurrent laryngeal nerve was evident in this study.

- Identification of the Recurrent Laryngeal Nerve trunk does not represent the nerve in its entirety.

The RLN deserves to be dissected in its full extent from root of neck to its entry into larynx so as to avoid injury to it.

- Most common site of injury to the nerve is at the Berry's ligament at its entry into Larynx.

The branches of the nerve were found to be more at risk of damage than the main trunk of RLN. Most common mechanism of injury was traction on the nerve and subsequent direct injury during dissection at Berry's ligament in an attempt to release the thyroid gland from trachea.

- Bilateral symmetry of the RLN is an evident fact, even though it is theoretically described as a remote possibility.

- A thorough knowledge of anatomy, performing an extracapsular thyroidectomy by delicate techniques, identification and preservation of RLN in its entire course and meticulous haemostasis are the mandates for normal voice after thyroidectomy.

\section{REFERENCES}

[1] Halsted WS. The operative story of goiter. Johns Hopkins Hospital Rep 1920;19:71. Reprinted in Halsted WS. Surgical papers. Vol 11. Baltimore: Johns Hopkins Press 1928:257.

[2] Standring S. Gray`s Anatomy. The anatomical basis of clinical practice. 41st edn. Elsevier 2015.

[3] Lee Mc Gregor`s synopsis of surgical anatomy. $12^{\text {th }}$ edn. Taylor and Francis 1986.

[4] DeGroot LJ, Larsen PR, Hennenman G. The thyroid and it's diseases. $6^{\text {th }}$ edn. New York: Churchill Livingstone 1996.

[5] Williams NS, Bulstrode CJK, O'Connel PR. Wound tissue repair and scars: in Bailey and Love's Short practice of surgery. $26^{\text {th }}$ edn. Taylor and Francis Group, CRC Press 2013; p. 24.

[6] Beauchamp RD, Evers BM, Mattox K. Sabiston text book of surgery. The biological basis of modern surgical practice. $20^{\text {th }}$ edn. Elsevier 2016. 
[7] Farquharson M, Moran B, Farquharson EL. Farquharson's text book of operative general surgery. $9^{\text {th }}$ edn. London: Hodder Arnold Taylor and Francis Group 2005.

[8] Hegner CF. A history of thyroid surgery. Annals of Surgery 1932;95(4):481-92.
[9] Nemiroff PM, Katz AD. Extra laryngeal divisions of recurrent laryngeal nerve. Surgical and clinical significance. American Journal of Surgery 1982;144(4):466-9.

[10] Suanders G, Uyeda RV, Karlan MS. Non recurrent inferior laryngeal nerves and their association with a recurrent branch. American Journal of Surgery 1983;146(4):501-3. 